\title{
Nie nadawajcie bezzębnych staruszek Kilka wspomnień z pracy \\ w Redakcji Muzyki Ludowej i Chóralnej Polskiego Radia
}

\author{
Do not broadcast toothless old ladies \\ A handful of memories from work \\ at the Editorial Office of Folk \\ and Choir Music of Polish Radio
}

DOI: 10.12775/LL.1.2021.008 | CC BY-ND 3.0 PL

MARIA BALISZEWSKA ethnomusicologist and journalist. She has been working for the Polish Radio since 1973. The author of many programmes on folk themes and recordings of Polish musical folklore, as well as studio and festival recordings. The founder and manager of the Radio Folk Culture Center (1994-2007), coordinator of the European Radio Union for traditional and folk music (1998-2009), judge for traditional music festivals and parades (including the National Festival of Folk Bands and Singers in Kazimierz and the International Competition of Folk Bands and Singers in Zakopane). In 1998 she initiated the Folk Festival of Polish Radio Nowa Tradycja. The author of many Muzyka Źródet albums, the series published by Polish Radio, as well as other albums, incl. Pod Tatrami na dolinie (Polskie Radio, Accord, PolyGram 1996), Pologne. Instruments Populaires (Radio France 1996), Welcome Europe 2004. New European Soundscapes (EBU, Polskie Radio 2004). A member of the Polish Composers Union and the Scientific Council of the Folk Artists Association. She was honored, among others, with the Golden Microphone (1993), the medal of Zygmunt Gloger (2003), the Minister of Culture and National Heritage Award (2007) and the Oskar Kolberg Award (2014).

KEYWORDS: folk music, radio, communism, archives, field recordings 
Jest rok 1973 - 2 maja. Zaczynam pracę w Redakcji Muzyki Ludowej i Chóralnej Polskiego Radia. Jestem szczęściarą - trzy dni wcześniej skończyłam studia muzykologiczne ze specjalizacją etnograficzną i już mam pracę. Nie wiem, co mnie tam spotka, ale czekam na to niecierpliwie. Już tydzień później moja pierwsza szefowa, Barbara Krasińska, wysyła mnie w teren. Jadę z wozem transmisyjnym i obsługą na Kurpie, do Ostrołęki. Oszołomiona tempem rozwoju wypadków, robię pierwszy raz w życiu samodzielnie nagrania zespołów biorących udział w przeglądzie kapel i śpiewaków z Kurpiów i Podlasia; choć trzeba dodać, że towarzyszą mi aż trzy osoby: dwóch techników oraz reżyser dźwięku (Andrzej Zygierewicz). Wracam $\mathrm{z}$ tarczą, choć dziś nie nadałabym na antenie żadnego z tych nagrań. Ówczesne zespoły pieśni i tańca nie miały zbyt wiele wspólnego z muzyką ludową znaną mi z wcześniejszych studenckich badań i obozów. Pierwszy miesiąc pracy w redakcji poświęcam na gruntowne studiowanie zawartości radiowego archiwum pod kątem tego, co mamy nadawać na antenie. I co tam znajduję? Pieśni ruchu robotniczego, pieśni historyczne w nagraniach radiowych orkiestr (wśród nich - o dziwo - pieśni powstań narodowych), dużo nagrań zespołów wykonujących muzykę ludową w opracowaniach (Kapeli Feliksa Dzierżanowskiego, kapeli akordeonistów Wesołowskiego, kapeli klarnecistów Maciejewskiego, orkiestr radiowych z rozgłośni regionalnych). Jest tam także cykl „Ulubione pieśni Lenina” (w skrzynce z muzyką narodów Związku Radzieckiego) oraz wiele innych ciekawostek nie mających wiele wspólnego z muzyką, której i o której uczyłam się w czasie studiów. Tej muzyki jest właśnie bardzo mało i tu widzę dla siebie pole do działania. Zachęca mnie do niego mój ówczesny kolega, Marian Domański, który cieszy się, że przybył mu w redakcji sprzymierzeniec, czyli ja.

Pierwsze zetknięcie z polityką przychodzi 22 lipca. W czasach PRL-u było to najważniejsze święto państwowe, obchodzone w na pamiątkę rocznicy ogłoszenia Manifestu PKWN. Do redakcji nadchodzą wytyczne, co mamy nadawać w przeddzień i w trakcie święta. Te wytyczne są następujące: dużo „Mazowsza” i „Śląska”, czyli czołowych w PRL-u zespołów pieśni i tańca, cieszących się dużą popularnością, choć nie zawsze dobrą sławą. Do legendy przeszła wpadka jednego z redaktorów, który podczas wizyty Breżniewa wpisał do programu Świniorza wykonywanego właśnie przez zespół „Mazowsze”, a w piosence tej padają słowa: „i choć padało choć było ślisko to się przywlekło to świniorzysko”. Redaktor nie ocalił swego stanowiska. Zdarzenie to było o tyle dziwne, że wtedy w radiu obowiązywała następująca procedura programowa: żadna audycja nie „idzie” na żywo, redaktor z gotowym tekstem udaje się najpierw do tzw. stylisty, który jako pierwsza instancja sprawdza audycję pod względem językowym, następnie tekst akceptuje cenzor, potem kierownik redakcji, i wreszcie redaktor naczelny. Teoretycznie mysz prześlizgnąc się nie może. A jednak udawało się czasem przemycać różne treści niezgodne $\mathrm{z}$ ideologią komunistycznych władz, chociażby pieśni religijne czy pieśni powstań narodowych. W takich sytuacjach trzeba było przeżywać katusze rozmów z cenzorem. Osobiście doświadczyłam tego wiele razy. Było tak choćby w przypadku pieśni z okresu powstania styczniowego o incipicie „Za plemion całych zmarnowane lata, co im w zepsuciu truto myśl i cześć”, którą postanowiliśmy w redakcji nadawać w stanie wojennym dla uczczenia rocznicy tego powstania. Do anegdoty przeszło też oskarżenie nas o dywersję, kiedy nadaliśmy Polkę węgierkę kapeli Bednarzy i okazało się, 
że utwór ten to znana amerykańska piosenka Yankee Doodle, która wówczas była sygnałem radiowym Głosu Ameryki. A już zupełnym curiosum był zakaz nadawania w audycjach muzyki skandynawskiej (jakiegokolwiek gatunku) po przyznaniu Lechowi Wałęsie nagrody Nobla w 1983 r.

Tak pracowaliśmy do roku 1989, celebrując stosownymi nagraniami państwowe i robotnicze święta, w miarę upływu czasu i wydarzeń historycznych ignorując te wytyczne coraz bardziej. W tamtym okresie szeroko pojęty folklor i muzyka ludowa w Polskim Radiu miały służyć propagandzie ustroju komunistycznego oraz „bratnich” sojuszy. W ramówce tygodniowej czasu na muzykę ludową było wtedy o wiele więcej niż obecnie. Jednak dwa razy w tygodniu po 35 minut nadawano cykl Słynne radzieckie zespoły ludowe, a polskie zespoły pieśni i tańca gościły na antenie co najmniej raz w tygodniu. W tej sytuacji wysiłki naszej maleńkiej czteroosobowej redakcji polegały na walce o to, by w radiu obecna była muzyka ludowa w wersji in crudo, którą później zaczęto nazywać muzyką tradycyjną. Pojawiała się ona w cyklu audycji o niefortunnej nazwie Wieś tańczy i śpiewa, przygotowywanej przez autorów z rozgłośni regionalnych Polskiego Radia: Jerzego Dynię (Radio Rzeszów), Barbarę Peszat-Królikowską (Radio Kraków), Stanisława Jareckiego (Radio Katowice), Annę Jachninę (Radio Bydgoszcz), Marynę Okęcką-Bromkową (Radio Olsztyn), Wandę Obniską (Radio Gdańsk), Mariana Obsta i Stanisława Młodziejowskiego (Radio Poznań), Bogumiłę Nowicką (Radio Lublin) i Piotra Gana (Radio Kielce). Przytaczam tę listę nazwisk, by podkreślić, że dla tego cyklu pracowały wówczas bardzo kompetentne osoby, które wybierały do publikacji prawdziwe muzyczne skarby. Audycje te miały charakter reportaży i niewiele z nich zachowało się do dziś w radiowych archiwach. Były nadawane w poniedziałki w Programie Pierwszym i miały dużą słuchalność sprawiającą, że do redakcji przychodziły całe worki listów. Podobny charakter miała niedzielna audycja Graj gracyku autorstwa szefowej Redakcji Muzyki Ludowej i Chóralnej Barbary Krasińskiej. Tak że Spotkania $z$ folklorem (w czwartki), które robiłam na zmianę z Anną Borucką-Szotkowską i Marianem Domańskim, wypełnione były polską muzyką ludową w wersji in crudo oraz prezentacją wybranych zawodów i twórców ludowych. Te programy w jakimśs stopniu równoważyły audycje przygotowywane na zamówienie polityczne. Zresztą stopniowo nawet wspomniany cykl Stynne radzieckie zespoły ludowe zaczął być wypełniany nie tylko nagraniami sztandarowych ansamblów (np. Mojsiejewa, Aleksandrowa czy innych państwowych chórów i orkiestr), ale muzyką bliższą autentyku, zwłaszcza z niektórych republik radzieckich, np. Gruzji, Armenii czy Azerbejdżanu. Radiofonie z tych miejsc przysyłały przykłady swojej tradycji muzycznej, która nie była tak mocno „skażona” politycznie jak ta udostępniana przez radio centralne ZSRR.

Pracowaliśmy w zasadzie w trójkę - Anna Borucka-Szotkowska, Marian Domański i ja - sami stawiając sobie zadanie (bo nikt tego od nas nie oczekiwał) polegające na dokumentacji polskiej muzyki ludowej w wersji autentycznej. Poszukiwaliśmy tego autentyku, jeżdżąc po wsiach, zapraszając niektórych wybitnych wykonawców do studia w Warszawie oraz odwiedzając festiwale i lokalne imprezy. Te wyjazdy miały służyć oczywiście antenie, czyli naszym audycjom, ale przede wszystkim krok po kroku tworzyliśmy w ten sposób archiwum, z każdym rokiem bogatsze, a dziś bezcenne. Nasze trio skupiało się na „pracy u podstaw”, ale czasem 
trzeba się było jednak poddać dyktatowi niektórych dyrektorów anten przysyłających polecenia w rodzaju: „Nie nadawajcie bezzębnych staruszek”, „Więcej »Mazowsza« i »Śląska«” albo „Więcej Kapeli Dzierżanowskiego w cyklu Raz na ludowo!”. My jednak stopniowo usuwaliśmy z anteny kiepskie muzycznie i pretensjonalne zespoły pieśni i tańca, zastępując je nagraniami kapel wprost ze wsi. Słuchacze wówczas reagowali żywiołowo. Był to czas przysyłania do redakcji listów z prośbami o nadawanie kapel rzeszowskich, kieleckich, mazowieckich, wielkopolskich czy lubelskich. A trzeba powiedzieć, że wtedy jeszcze było tych kapel - i to znakomitych - całkiem dużo, bo wesela odbywały się cały czas z tradycyjną oprawą muzyczną. Kiedy radiowy samochód marki Robur zajeżdżał do wsi na umówione wcześniej nagrania, cała wieś nas witała. A później podczas nagrań ludzie stali pod oknami i słuchali, komentując występy śpiewaków i muzykantów. Dla mnie tamten czas, choć to lata PRL-u , był czasem wspaniałym, pełnym ciekawych ludzi i muzyki z XIX-wiecznym rodowodem. Dziś takich nagrań jak wówczas nie można już zrobić. Nie ma tamtych muzykantów, nie ma śpiewaków weselnych... „minęli się”, jak mówią górale. 